\title{
Specifying DHW heat demand profiles according to operational data: enhancing quality of a DH system model
}

\author{
Stanislav Chicherin ${ }^{1 *}$, Andrey Zhuikov², Mikhail Kolosov², Lyazzat Junussova ${ }^{3}$, Madina \\ Aliyarova $^{3}$, and Aliya Yelemanova ${ }^{3}$ \\ ${ }^{1}$ Omsk State Transport University (OSTU), 644046, 35, Marx avenue, Omsk, Russia \\ ${ }^{2}$ Siberian Federal University, 660041, Svobodny Ave. 79, Krasnoyarsk, Russia \\ ${ }^{3}$ Non-profit JSC Almaty University of Power Engineering and Telecommunications, Almaty, \\ Kazakhstan
}

\begin{abstract}
For a DH network a meticulous analysis is required to detect a correlation of a reduction in energy demand from one year to another. The factors, which lead to such inconsistency, force an energy company (1) to modernize equipment at a consumer side and (2) to lower network operating temperatures. It results into so called fourth generation district heating (4GDH). The current research focuses on large-scale DH systems and DHW as second largest share of heat demand. The heat delays, thermal inertia and DHW consumption patterns are specified further since they might represent a natural heating accumulator. In this case, daily flow changes are considered, as they influence a DH system performance and desirable TES capacity. However, more precise profiles can be achieved by detecting the actual flow curve, and measuring the temperature difference between substation supply and return line. The dimensioning of $\mathrm{DH}$ systems requires comprehensive understanding of simultaneity factors. Thus, we consider substations with DHW preparation to choose the optimal size of the heat distribution network according to the new method. Case study is a DH system in Omsk, which includes residential houses (both SH and DHW coverage), and university buildings (more demand results from process heat). The operation of the system was studied for the period from the 1st of January to 31st of December 2020. We suggest a TES with a capacity of $0.04 \mathrm{MWh}$; based on the traditional temperature range, the volume is about $0.5 \mathrm{~m} 3$. Daily compensation time is $2-3$ hours, when there is a reduction in the supply flow rate of $1500 \mathrm{t} / \mathrm{h}$ with minimum DH plant make-up. The entire DH system requires about $400 \mathrm{t}$ of hot water make-up to reach the quasi-steady state conditions after the night DHW shutdown. Using the threshold of the traditional model, it hardly fits an operational value - it is better set according to novel method (0.1 MW). For similar relations between circulation and DHW flow rates, the systems with a HE result in higher circulating flows than the substations with no one. The consumer benefit from consuming DHW and heat according to more accurate profiles accounts 1.72 billion USD. It is quantified by considering avoiding using a back-up electricity source to ensure DHW
\end{abstract}

*Corresponding author: man_csv@hotmail.com 
service when a DH plant supplies enough heat. Moreover, if a TES is controlled according to the method detailed, it alleviates the stress for intermittent operation by compensating the transients of SH and DHW loads. 4GDH concept should be considered according to: (1) the operational data, (2) new DHW demand assessments, and (3) using TES to buffer peaks.

\section{Introduction}

For such a complicated system as a DH network a meticulous analysis is required to detect a strong correlation of a reduction in energy demand from one year to another to a single cause. As usual, there are several factors, which may lead to such inconsistency [1]. These factors force an energy company to upgrade equipment at a consumer side and to reduce network operating temperatures, which results into so called fourth generation district heating (4GDH) [2]. 4GDH systems establish new business models for service providers since there is the possibility to provide both heating and cooling services or to charge both heat and electricity consumption of a substation in a single bill [3].

The 4GDH concept becomes a complete shift in DH development and is characterized by a low supply temperature and smart control of substations [4]. The same way, Farouq et al. [5] detected malfunction of some substations compared to their reference-group. The reason is the same as well - spoiled equipment or an inefficient tuning of different control parameters at the target substation.

Braas et al. [6] indicate the correlation of the return temperature with circulation losses and useful energy demand for DHW, especially for instantaneous systems. The Kristensen et al.'s [7] database is stipulated by using two data fields to obtain only the single-family houses in Aarhus, Denmark municipality, so there is no particular focus on DHW consumption of residential multi-storey buildings.

At the same time, new city areas involves primarily floor heating that does not require high temperatures, so the temperature in the supply line of the $\mathrm{DH}$ network can be $65^{\circ} \mathrm{C}$. The supply temperature of a $4 \mathrm{GDH}$ system during the year is $65^{\circ} \mathrm{C}$ and is fixed regardless of a season. If the temperature is lower, there is a risk of exposure to Legionella in DHW systems [8]. In Russia, main funds allocated for the DH system modernization are spent on pipelines repair since a DH network is the most vulnerable element of a system [9]. Shabby condition of a distribution system may even limit maximum supply temperature and make a DH system unacceptable for operating according to design temperature curve (e.g. 150/70).

Waste heat may serve as primary energy for a heat pump [10]. That proofs feasibility of new idea of connection in cascade to the return line of existing DH systems [8]. Arabkoohsar et al. [11] raise a pertinent question why individual heat pumps for DHWpreparation are not cost-effective, and figured out a reason - a very low utilization factor of heat pumps in that case.

The total peak demand is not as high during weekdays as peak DHW demand persists earlier in the morning whilst peak active occupancy happens later in the day [12]. However, Saletti et al. [13] reveal a higher temperature that derives from the fact that the optimal supply temperature reaches the substation heat exchanger some time after it exits a DH plant, due to the system operational delays. The evaluation technique implemented in the developed model takes also into account thermal inertia of a DH network considering the time spent by the hot water to flow from a DH plant to a consumer substation [14].

The simulated operation of a 4GDH in Ref. [15] highlights the need for advanced design techniques. The reason is high interaction of all system components, which makes the decision-making process more complex. For instance, it does not always make sense to 
discharge all available thermal energy storage (TES) to cover DHW peak. The TES size to cover the daily variations and the source peak power is tabulated in Ref. [16].

In Ref. [17], the Turin (Italy) DH system is detailed. The same with the DH system considered here, it contains both the central storage (its total volume is $12,500 \mathrm{~m} 3$ ) and the same heating devices - radiators, which are still mainly applied instead of warm floors or panel heaters.

Analysis of thermal transient processes (including peaks and energy delays) is utterly dependent on the performance and accuracy of a DH system model. In the proposed model the internal and solar gains are used more efficiently than they would be used in a real building [18].

Turski et al. [19] determined the rate of low outdoor temperature periods as not high, especially 3-, 4- and 5- day episodes are barely possible from the statistical point of view. The frequency and duration of episodes with the lowest values of external temperature were assigned to the percentage values of the maximum heat production of a DH plant.

The current research focuses on large-scale DH systems and DHW as second largest share of heat demand. The heat delays, thermal inertia and DHW consumption patterns are specified further since they might represent a natural heating accumulator. In this case, daily flow changes are considered, as they influence a DH system performance and desirable TES capacity.

\section{Materials\&Methods}

There is still some heat quantity in Russia that consumers directly extract from the primary DH water and heat meters are readily available for this purpose. Substations are equipped with a water flow meter to measure this amount of water. However, these meters are pretty cost-intensive and need connections to both supply and return lines.

It is typically advisable to charge for heat delivered in some way to exclude unnecessary heat consumption to the benefit of the service provider and the consumers. Instead, DHW demand is traditionally assessed according to

$$
Q_{h m}=\frac{a N\left(t_{D H W}-t_{c}\right) 10^{-6}}{T}+Q_{h l}
$$

where a - specific DHW volumetric demand [1 per person];

$\mathrm{N}$ - number of inhabitants (students, etc.);

tDHW - DHW temperature $\left[{ }^{\circ} \mathrm{C}\right]$, usually set to $60^{\circ} \mathrm{C}$;

tc - cold water temperature, usually set to $5^{\circ} \mathrm{C}$;

$\mathrm{T}$ - hours of daily DHW demand [h]

Qhl - heat losses in a DHW system [MW].

A variety of required information is not available. Therefore, average values are traditionally applied. However, more precise profiles can be achieved by detecting the actual flow curve, and a means of measuring the temperature difference between substation supply and return line, which permits the meter to calculate the amount of heat extracted by integrating the two quantities. Recorded hourly data is delivered automatically to the energy supplying company. If a TES is installed, it is as follows.

$$
Q_{h m}=\frac{c}{3.6} \cdot G_{h m}\left(t_{D H W}-t_{c}\right)\left(1+k_{h l}\right)
$$

where $\mathrm{khl}$ - heat loss factor, according to Table 1. 
Table 1. Heat loss factor according to the type of a DHW system.

\begin{tabular}{|c|c|c|}
\hline \multirow{2}{*}{ Type of a DHW system } & \multicolumn{2}{|c|}{ Heat loss factor, khl } \\
\cline { 2 - 3 } & $\begin{array}{c}\text { separate DHW pipe after a } \\
\text { group substation }\end{array}$ & no group substation \\
\hline Properly insulated, no towel rail & 0.15 & 0.1 \\
\hline $\begin{array}{c}\text { Ditto, equipped with a towel rail } \\
\text { Poorly insulated, equipped with } \\
\text { a towel rail }\end{array}$ & 0.25 & 0.2 \\
\hline
\end{tabular}

Once DHW heat demand is known, we should take into account it is not constant over time. The mass flow rate on the secondary side of the DHW heat exchanger is determined by the energy balance $[\mathrm{t} / \mathrm{h}]$, the same as Vandermeulen et al. [20] do

$$
G_{D H W}=\frac{Q_{D H W}}{c \cdot\left(\tau_{\text {1.b.p. }}-\tau_{\text {2.b.p. }}\right)}
$$

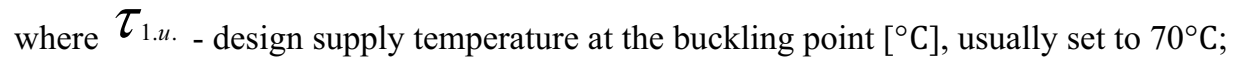

$\tau_{\text {2.b.p. }}$ - design return temperature at the buckling point $\left[{ }^{\circ} \mathrm{C}\right]$, usually set to $30^{\circ} \mathrm{C}$.

If a DHW system is a direct system that means that there is no HE or water tank, and all heat demand should be met instantaneously [20]. If there is either HE or water tank [MW]:

$$
Q_{D H W}=Q_{D H W}^{a v}
$$

Different consumers have different DHW profiles and thus requirements for design load, which allow different dimensions for pipes in the network and house connection pipes. For instance, DH substation has an actual demand of $4 \mathrm{~kW}$ and a design demand of $32 \mathrm{~kW}$. If former is applied, a DH system in general requires smaller piping than in case of $32 \mathrm{~kW}$, although network dimensions depend highly on simultaneity factors. Demonstration of the 4GDH in EU [3] has shown that the dimensioning of DH systems in areas with low energy single family houses requires especially comprehensive understanding of simultaneity factors. Thus, greater consideration should be given to the substations with DHW preparation and the SH systems to choose the optimal size of the heat distribution network according to Eqs. 5-6 [MW]

$$
Q_{D H W}=Q_{D H W}^{\max }
$$

where

$$
Q_{D H W}^{\max .}=\kappa \cdot Q_{D H W}^{a v}
$$

where $\kappa$-simultaneity factor, set according to Tables 2 and 3;

$Q_{D H W}^{a v}$ - the measured average amount of DHW heat demand of consumers connected to the $\mathrm{DH}$ network without storage operation and serving as a reference [MW]. 
Table 2. Simultaneity factor for non-residential buildings.

\begin{tabular}{|c|c|}
\hline Type of building and a bathroom location & Simultaneity factor \\
\hline Hospitals & 1.73 \\
\hline Hospitals for infectious diseases & 2.07 \\
\hline Hotel bathrooms & 1.00 \\
\hline Hotels with showers & 2.62 \\
\hline Health centres and clinics & 4.47 \\
\hline Day-care nurseries & 5.43 \\
\hline Round-the-clock care nurseries & 4.8 \\
\hline Educational institutions with showers & 3.60 \\
\hline Schools & 6.86 \\
\hline Boarding schools & 4.80 \\
\hline Theatres & 2.11 \\
\hline Administration buildings & 6.86 \\
\hline B\&Bs and motels & 2.81 \\
\hline Hotels with several separate bathrooms & 2.06 \\
\hline $\begin{array}{l}\text { Hotels, where up to } 25 \% \text { of rooms are } \\
\text { equipped with separate bathrooms }\end{array}$ & 2.50 \\
\hline $\begin{array}{c}\text { Hotels, where up to } 75 \% \text { of rooms are } \\
\text { equipped with separate bathrooms }\end{array}$ & 2.40 \\
\hline $\begin{array}{l}\text { Hotels, where all the rooms are equipped with } \\
\text { separate bathrooms }\end{array}$ & 2.16 \\
\hline Barber shops & 3.22 \\
\hline Hardware stores & 6.86 \\
\hline Grocery stores & 4.00 \\
\hline Stadiums, rinks, gyms, fitness halls & 2.00 \\
\hline Swimming pools & 2.00 \\
\hline $\begin{array}{l}\text { Small industrial facilities (up to } 23.3 \mathrm{~W} \text { per } 1 \\
\mathrm{~m} 2 \text { area) }\end{array}$ & 9.60 \\
\hline $\begin{array}{l}\text { Large industrial facilities (more than } 23.3 \mathrm{~W} \\
\text { per } 1 \mathrm{~m} 2 \text { area) }\end{array}$ & 8.40 \\
\hline
\end{tabular}


Table 3. Simultaneity factor for low-rise residential buildings.

\begin{tabular}{|c|c|c|c|c|c|c|c|c|}
\hline $\begin{array}{c}\text { Number of } \\
\text { inhabitants }\end{array}$ & $\mathbf{1 5 0}$ & $\mathbf{2 5 0}$ & $\mathbf{3 5 0}$ & $\mathbf{5 0 0}$ & $\mathbf{7 0 0}$ & $\mathbf{1 0 0 0}$ & $\mathbf{1 5 0 0}$ & $\mathbf{2 0 0 0}$ \\
\hline Simultaneity factor & 5.15 & 4.5 & 4.1 & 3.75 & 3.5 & 3.27 & 3.09 & 2.97 \\
\hline
\end{tabular}

Table 4. Simultaneity factor for multi-storey residential buildings.

\begin{tabular}{|c|c|c|c|c|c|c|c|c|}
\hline $\begin{array}{c}\text { Number of } \\
\text { inhabitants }\end{array}$ & $\mathbf{2 5 0 0}$ & $\mathbf{3 0 0 0}$ & $\mathbf{4 0 0 0}$ & $\mathbf{5 0 0 0}$ & $\mathbf{6 0 0 0}$ & $\mathbf{7 5 0 0}$ & $\mathbf{1 0 , 0 0 0}$ & $\mathbf{2 0 , 0 0 0}$ \\
\hline Simultaneity factor & 2.9 & 2.85 & 2.78 & 2.74 & 2.7 & 2.65 & 2.6 & 2.4 \\
\hline
\end{tabular}

Simultaneity factor represents difference between actual and design heat supply according to the designated number of the inhabitants. It also serves as a reference value, the same as a column 'Reference network losses' in Ref. [21] does.

If no TES is installed, heat demand is follows

$$
Q_{h \max }=\frac{c}{3.6} \cdot\left(G_{h \max }+G_{h m c} k\right)\left(55-t_{c}\right) \text {. }
$$

The temperatures at the DHW side, indicated by tc and tDHW, as mentioned, are the temperatures of cold water and DHW, respectively and are taken to be known and fixed over time, e.g. 5 and $60^{\circ} \mathrm{C}$. Vandermeulen et al. [20] assume these temperatures constant as well.

Case study object is a high temperature DH system in Omsk [22], which includes heat distribution system with head pipes of $800-1000 \mathrm{~mm}$ of diameter and operates at design temperatures of $70^{\circ} \mathrm{C}$ in return line and $150^{\circ} \mathrm{C}$ in supply one, and pressure between $8-14$ bar [23]. Several buildings were opted for the thorough study. Buildings denoted as buildings 2, 7-11 are residential houses, in which heat load includes both SH and DHW coverage. University buildings are 1, and 3-6. In these buildings, a substantial proportion of demands results from process heat and less DHW for washing purposes only. Buildings 3, 5 and 7-9 have a mixed DHW utilization (both open connection and a HE), while substations of buildings 2, 10-11 are not equipped with latter (Fig. 1).

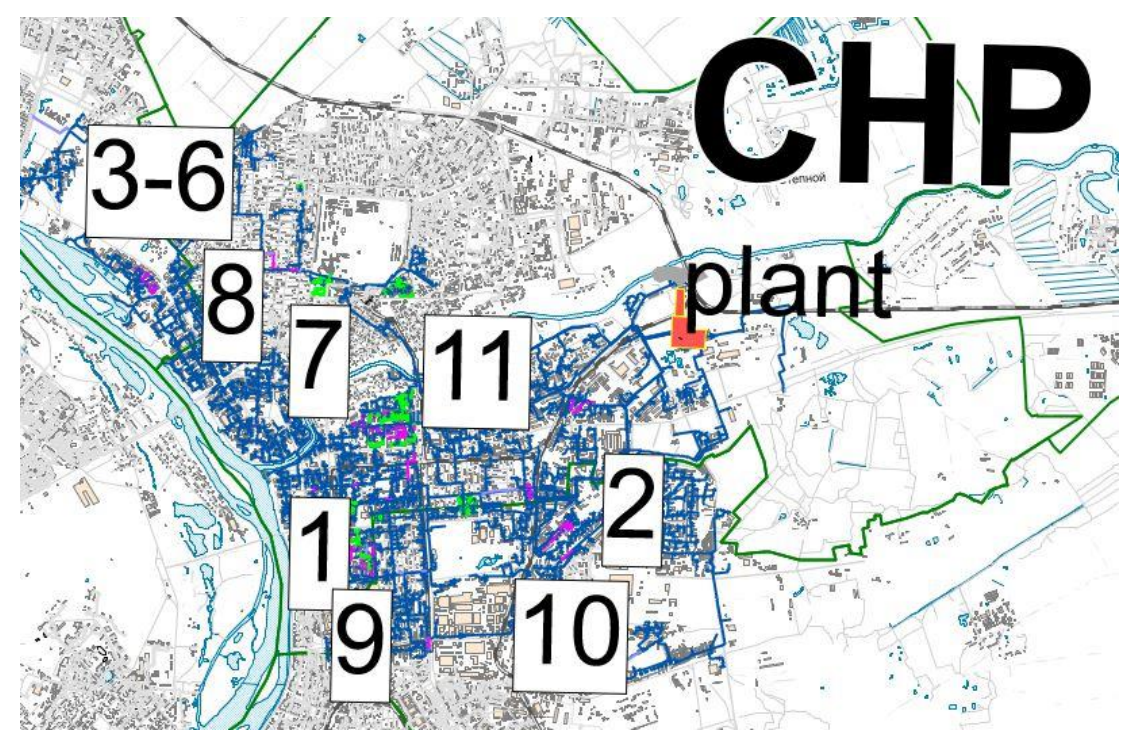

Fig. 1. DH system layout with buildings labels. 
Building 1 includes a canteen that has a large heating load due to process heat. The supply temperature of the primary side is assumed $150^{\circ} \mathrm{C}$, the return temperature $70^{\circ} \mathrm{C}$. For covering the heating demands in the buildings, a $\mathrm{SH}$ system with supply temperature of $95^{\circ} \mathrm{C}$ with a return temperature of $70^{\circ} \mathrm{C}$ is assumed the same with Wirtz et al. [15]. The operation of the system was studied for the period from the 1st of January to 31 st of December 2020. Unlike us, Luc et al. [18] simulate the operation of the system starting from the 1st of October to 30th of April. The reference DH system has a validated maximum daily heat demand of $55,563 \mathrm{MW}$ at a winter average outside temperature of $-30.6^{\circ} \mathrm{C}$ [24]. In order to have the most realistic heat demand profiles, daily resolved customer heat consumption profiles were taken. Thanks to the network operator, the data was arranged on a substation basis before being implemented into the simulation tool. Overall, Omsk DH system includes also circa. 11,000 substations with $\sim 9000$ buildings up to 15 storeys connected. The same with Hammer et al. [21], in order to address data consistency problems, options like filling in gaps with average values in the case of short time outages or the use of load profiles of similar consumers as a substitute were applied.

\section{Results \& Discussion}

Fig. 2 presents the weighted daily heat demand for several days and the relation of total energy to the useful energy for DHW.

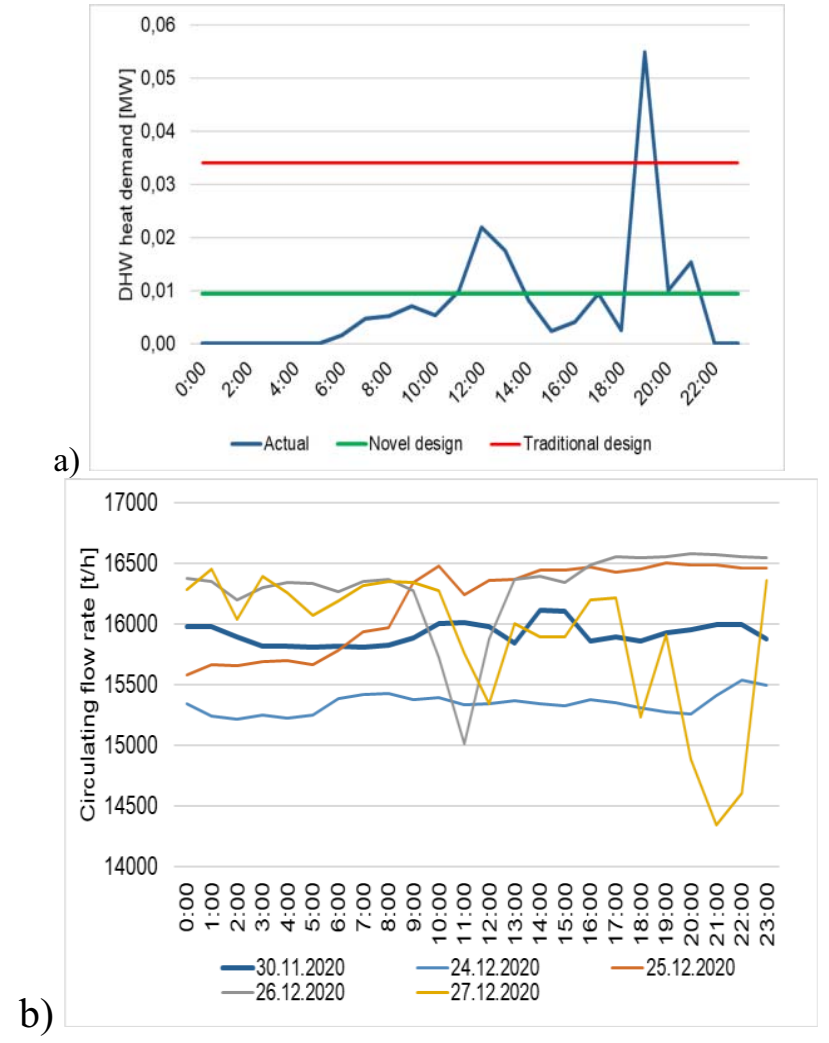

Fig. 2. Cumulated daily heating and DHW demands of one building (University, building\#1) for the same days: a) DHW demand, b) Total SH+ DHW flow rates. 
According to operational experience, the hydraulic pumps on the primary side are controlled to ensure a fixed temperature to the DHW system of a building (secondary side of a DHW HE) while the temperature difference on the primary side is let to fluctuate. Differently, at the consumer substations, which include the SH HE, the hydraulic pump is controlled to maintain a fixed differential pressure at SH system.

For substation of a building\#1 (Fig. 2a), the optimal solution suggests a TES with a capacity of $0.04 \mathrm{MWh}$ (compared to $1.72 \mathrm{MWh}$ in Ref. [15]). Based on the temperature range of the heat storage $\left(20-90^{\circ} \mathrm{C}\right.$ ), this equals a water volume of $0.49 \mathrm{~m} 3$ (compared to $21.16 \mathrm{~m} 3$ in Ref. [15]). The plots come in duration- curve format to better see the differences. According to the figure, the DHW HE in the substation is only 40 min a day in full service. The lowest flow rate occurs on the 24th of December as there is no intense SH energy demand on this day.

We conclude that temperatures below $-30^{\circ} \mathrm{C}$ occur $37 \mathrm{~h} /$ year (Fig. 2b), and it is unlikely that the coldest weather periods may occur immediately after each other. Moreover, daily compensation time is $2-3$ hours, when there is a reduction in the supply flow rate of 1500 $\mathrm{t} / \mathrm{h}$ with minimum DH plant make-up. Turski et al. [19] statistically assume that temperatures below $-15^{\circ} \mathrm{C}$ happen $6 \mathrm{~h} /$ year, and they, the same, predict that the worst-case scenario can occur immediately after each other. Thus, the best compensation time of $4.2 \mathrm{~h}$, with an increase in the supply medium temperature of $10^{\circ} \mathrm{C}$ and with minimum source heat output reduction of $5 \%$ is not enough.

In order to better assess the impact of the circulation heat demand, the circulating was adjusted for each section. These values are shown by Fig. $2 b$. The relative reduction in the discrepancy between supply temperature and soil temperature (that is assumed as $2{ }^{\circ} \mathrm{C}$ in winter) is $14^{\circ} \mathrm{C}$ that gives the clear expression of a reduction in heat losses from the pipelines, varies from a minimum of $12.3 \%$ for higher outdoor temperatures to a maximum of $43.8 \%$ for lower outdoor temperatures, with an average reduction of $31.5 \%$ during the studied time period. Saletti et al. [13] assume soil temperature as $10^{\circ} \mathrm{C}$ in the simulations that results in a reduction in heat losses from a heat distribution system. The reduction varies from a minimum of $3.1 \%$ for higher outdoor temperatures to a maximum of $20 \%$ for lower outdoor temperatures, with an average value of $8.8 \%$ over the studied time period [13].

In the example illustrated in Figure 2b, the DHW heat demand according to the novel design method is evaluated with a least-squares fit of a piecewise linear function although it can be assessed also with interval-specific averages or median values. There is a trade-off between the rate of false peaks and potential faults, which fall within the acceptable limits. Fig. 3 indicates a comparison of the reference-group based approach with the baseline global outlier detection models, i.e. of the case study in the proposed and the traditional DHW demands and the threshold.

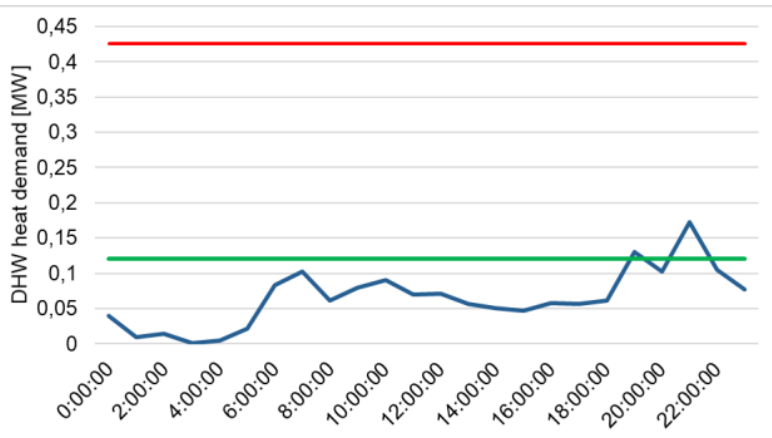

a)

—Actual -Novel design —Traditional design 


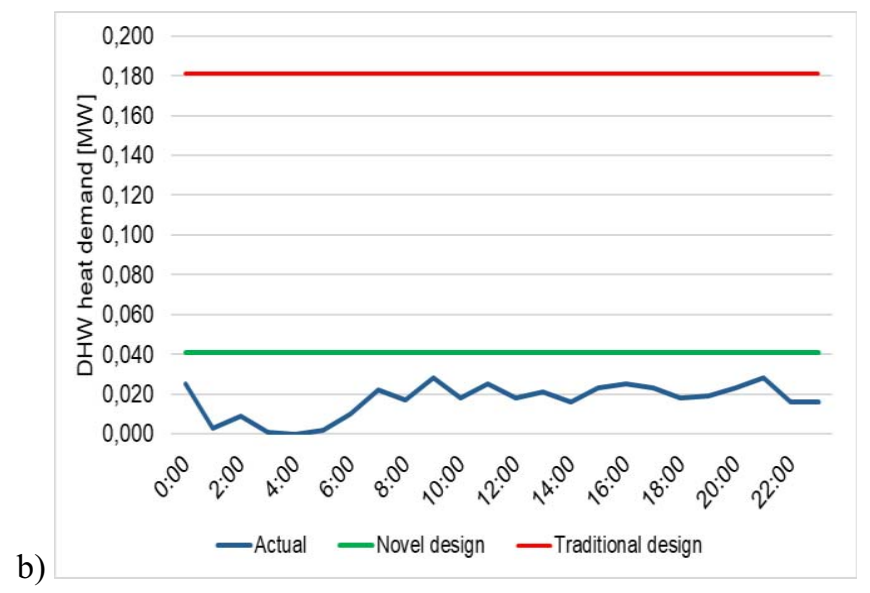

Fig. 3. Heat load variations illustrated using averaged hourly heat load profiles for the residential multi-storey building constructed in a) 1981 (building \#2), and b) 2014 (building \#7) during the same day.

The lines show almost the same regressions through the DHW preparation systems of the same building types [6]. However, the modelled temperature in the older building varies more significantly than in the new ones. It is caused by the way the DHW system is controlled combined with its larger heat demand (up to 50\%). Volkova et al. [8] claim even higher share of DHW capacity, which is around 55\%. For all of the non-residential buildings, there is a visible impact of the internal heat gains, which is corroborated by Luc et al. [18].

At the considered time instant the farthest nodes are the hottest ones (about $90^{\circ} \mathrm{C}$ ) while the closest nodes result the coldest ones (about $82^{\circ} \mathrm{C}$ ). Moreover, there is no heating demand only at 3:00 and 4:00. Unlike us, Barone et al. [14] explain such a behaviour by considering that the night setback of heat supply to DH consumers is scheduled at 23.00. Therefore, they detect no heating demand much earlier - at 23:10.

A thorough analysis should be triggered when a value is detected outside the area inbetween the lower and upper linear thresholds that typically are set at an empirically (and subjectively) determined "reasonable" distance from the temperature-dependent DHW heat demand, e.g. Fig. 3a or Fig. 3b. The reasons are the shabby quality of constructions of DH networks applied earlier, thermal insulation, valves, rickety level of automatic control processes of transmission, distribution and malfunction at a substation [9].

Fig. 4 compares the flow rates required for supplying the DHW demand of one randomly selected residential house over the three typical weekday, weekend and holiday days. 


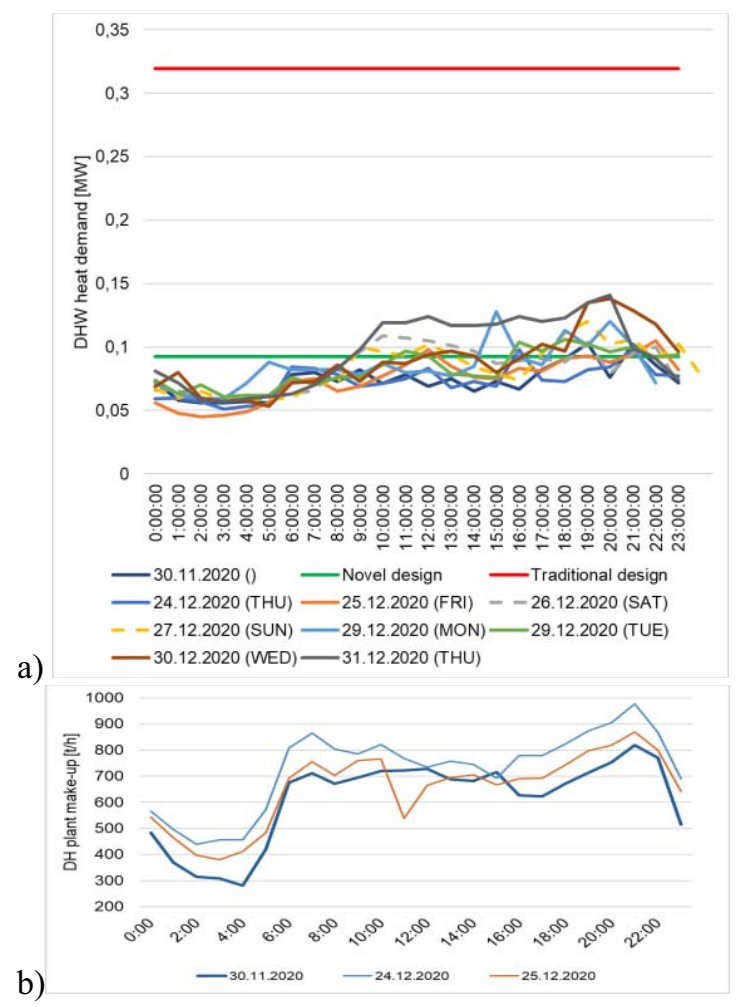

Fig. 4 a) DHW heat demand of the same residential building (\#7) in 9 sample days; b) DH plant make-up compensating DHW consumption of buildings with no heat exchanger for 3 days in different parts of winter.

Contribution of the various components are similar (between 400 and $800 \mathrm{t} / \mathrm{h}$ ) except that for the 24.12.20. Results show that the entire DH system requires about $400 \mathrm{t}$ of hot water make-up to reach the quasi-steady state conditions after the night DHW shutdown. Guelpa et al. [17] conclude that the whole system requires about $330 \mathrm{MWh}$ of energy to achieve the pseudo-steady state conditions after the night shutdown. Contribution of the various components is much larger (between 50 and $100 \mathrm{MWh} /$ day) except that for the radiators (13 MWh).

During weekend day, the morning and evening weekday peaks are not equal with the difference at approximately $43 \mathrm{kWh}$. Such a behaviour can be explained by considering that the night setback of heat supply to DH users happens later. The trend is more noticeable for residential buildings, than for universities. Further, the decrease was lowest for the case with the highest DHW share and plot ratio. Accordingly, lower DHW powers would benefit the flow rates to residential buildings compared to the universities, but still in the assessed range of $23 \%$.

Using the criterion that the boundary of the traditional model of $0.32 \mathrm{MW}$ hardly fit an operational threshold and considering the make-up rate profile, it is better set according to novel method $(0.1 \mathrm{MW})$ for a multi-storey residential building for Dec'20. In the colder months of Nov'20 and Dec'20, there are two large daily peaks in demand as these months have high SH energy demand (Fig. 4a). As far as this simulation period is concerned, the water is actually supplied at a fixed temperature higher than $90{ }^{\circ} \mathrm{C}$, while in the original control strategies it varies between $80^{\circ} \mathrm{C}$ and $95^{\circ} \mathrm{C}$. Unlike Harney et al. [12], Fig. 4a shows that peak DHW demand for weekdays occurs at approximately 8 p.m. It is also a reason for 
the two daily peaks in water make-up rate in Fig. $4 \mathrm{~b}$ as during these days there is a peak in DHW load in the morning and a peak in SH demand in the late evening. It clarifies the need for a TES with a capacity of $0.1 \mathrm{MWh}\left((0.15-0.1)^{*} 2\right)$ to be installed that accumulates a water volume of $12 \mathrm{~m} 3$ (temperature range $50-70^{\circ} \mathrm{C}$ ).

An issue in comparison of a DH system operation is that the daily heat demand changes over the season and depends on outdoor temperature [1]. This creates thermal peaks that may result into non-optimal control of CHP and heat-only boiler plants, and thus increase fuel consumption. When a DHW-SH ratio is taken into account, different methods are applicable, e.g. the design value of one certain objective or a specific weighting based on an entire control strategy [2].

The baseload is quite high that can be explained by the lower share of DHW demand in older buildings with no DSM measures that was around $25 \%$. That results into lower specific SH and ventilation demand in buildings with high energy-efficiency [8].

The daily storage is accumulated at building envelopes and TES, which is located at either centralized location or at a substation. For a local DH network, the choice is easy to make, since the consumers are located not far from a DH plant. As for a large DH network, storages are better installed for compact consumer groups (districts, boroughs, etc., even quarters) and there will be no consumers with no centralised TESs [21]. The reason is long and meshed DH networks characterised by high heat loses.

In all the above cases in this paper, daily storage is sized at $100 \%$ maximum daily storage size distributed to all buildings. This idea is supported by Jebamalai et al. [16]. Secondly, different TESs should also be integrated in such a network as they are required for a system operation during hours of peak demand [4]. Annually heat from TES may cover circa. $11 \%$ of heat provided to consumers. That could be compared to covering $25 \%$ of energy supplied to customers in case of a cascade connection detailed in Ref. [8].

When comparing any model, e.g. a model presented in Ref. [20], with the present model, the performance of the two simulations is very similar. Vandermeulen et al. [20] show that when the design supply temperature enters the substation, the prediction of return temperature is very accurate (with an error lower than $0.05^{\circ} \mathrm{C}$, we have $1{ }^{\circ} \mathrm{C}$ ), when the higher supply temperature enters the substation, there is a larger deviation of about $0.5^{\circ} \mathrm{C}$ (we have $2-3^{\circ} \mathrm{C}$ ). As for the actual operation, referring to Figs. 2-4, we expect much larger deviations of 5 and $10^{\circ} \mathrm{C}$ respectively and conclude that the performance of these models mostly depends on their ability to take highly fluctuating DHW consumption into account.

In some cases, a lack of dynamic excitation in the operational data would make the identification of certain reasons complicated, whilst in other cases, parameters estimates may deviate from their expected values due to specifications of model structure or substation control. Secondly, there is definite possibility of the prior assumptions just not conforming the actual conditions in the studied substations and houses that may have been the reason for the excessive DHW consumption. The same excuse is presented by Kristensen et al. [7]. Lesko et al. [25] show that the software may optimize the time of starts and stops of production units in a correct way to make it suitable for the actual operation. However, it has been tested separately, that a decrease of start cost would result in another scenario, with peak boiler turned off in the middle of the consumption period.

The demand curves in Figs. 3 and 4 show, that for similar relations between circulation and DHW flow rates, the systems with a single HE result in higher circulating flows than the substations with no one. Braas et al. [6] achieve the same conclusion, but the difference is related to pre-heater and after-heater configuration compared to a single heat exchanger. However, to make a valid comparison, the same buildings have to be simulated with both systems [6], as we do below. 


\section{Conclusion}

The consumer benefit from consuming DHW and heat according to more accurate profiles takes into account electricity for housing, general, and industrial purposes; the savings are estimated at 1.72 billion USD. Because DHW is mostly a non-replaceable energy source, except in limited cases such as a single family house, the consumer benefit from the methodology is evaluated by considering the benefit from avoiding using a back-up electricity source, namely, a boiler, to ensure DHW service when a DH plant supplies enough heat rather than from the concept of switching to completely another energy source.

Moreover, if a TES is controlled according to the method detailed, it alleviates the stress for intermittent operation by compensating the transients of SH and DHW loads. TES may be connected to a DH network in several ways. Further research questions are raised by the integration of DHW and SH heat demands using highly fluctuating renewable sources in terms of demand shift by large thermal storage. 4GDH concept should be considered, followed by appropriate demonstration projects according to (1) the operational data, (2) new DHW demand assessments, and (3) using TES to buffer peaks

The reported study was funded by the Administration of Krasnoyarsk Krai and the Krasnoyarsk Krai Foundation for Support of Scientific and Technical Activity.

\section{References}

1. Chicherin, S. V. Comparison of a district heating system operation based on actual data - Omsk city, Russia, case study. Int. J. Sustain. Energy 38, 603-614 (2019).

2. Chicherin, S., Junussova, L. \& Junussov, T. Advanced Control of a District Heating System with High Residential Domestic Hot Water Demand. E3S Web Conf. 160, (2020).

3. Buffa, S., Cozzini, M., D’Antoni, M., Baratieri, M. \& Fedrizzi, R. 5th generation district heating and cooling systems: A review of existing cases in Europe. Renew. Sustain. Energy Rev. 104, 504-522 (2019).

4. Chicherin, S., Junussova, L. \& Junussov, T. Study on the modernisation of an extraworn district heating (DH) system in Russia: low temperature $\mathrm{DH}$ and 4 more options processing. E3S Web Conf. 143, (2020).

5. Farouq, S., Byttner, S., Bouguelia, M.-R., Nord, N. \& Gadd, H. Large-scale monitoring of operationally diverse district heating substations: A reference-group based approach. Eng. Appl. Artif. Intell. 90, 103492 (2020).

6. Braas, H., Jordan, U., Best, I., Orozaliev, J. \& Vajen, K. District heating load profiles for domestic hot water preparation with realistic simultaneity using DHWcalc and TRNSYS. Energy 117552 (2020) doi:10.1016/J.ENERGY.2020.117552.

7. Kristensen, M. H., Hedegaard, R. E. \& Petersen, S. Long-term forecasting of hourly district heating loads in urban areas using hierarchical archetype modeling. Energy 201, (2020).

8. Volkova, A. et al. Energy cascade connection of a low-temperature district heating network to the return line of a high-temperature district heating network. Energy 198, 117304 (2020).

9. Chicherin, S., Junussova, L., Junussov, T. \& Junussov, C. Comparing strategies for improving thermal performance of an existing district heating (DH) network: low temperature DH in Omsk, Russia. E3S Web Conf. 173, (2020). 
10. Meesenburg, W., Ommen, T., Thorsen, J. E. \& Elmegaard, B. Economic feasibility of ultra-low temperature district heating systems in newly built areas supplied by renewable energy. Energy 191, 116496 (2020).

11. Arabkoohsar, A. \& Alsagri, A. S. A new generation of district heating system with neighborhood-scale heat pumps and advanced pipes, a solution for future renewablebased energy systems. Energy 193, 116781 (2020).

12. Harney, P., Gartland, D. \& Murphy, F. Determining the optimum low-temperature district heating network design for a secondary network supplying a low-energy-use apartment block in Ireland. Energy 192, (2020).

13. Saletti, C., Zimmerman, N., Morini, M., Kyprianidis, K. \& Gambarotta, A. Enabling smart control by optimally managing the State of Charge of district heating networks. Appl. Energy 116286 (2020) doi:https://doi.org/10.1016/j.apenergy.2020.116286.

14. Barone, G., Buonomano, A., Forzano, C. \& Palombo, A. A novel dynamic simulation model for the thermo-economic analysis and optimisation of district heating systems. Energy Convers. Manag. 220, (2020).

15. Wirtz, M., Kivilip, L., Remmen, P. \& Müller, D. 5th Generation District Heating: A novel design approach based on mathematical optimization. Appl. Energy 260, 114158 (2020).

16. Jebamalai, J. M., Marlein, K. \& Laverge, J. Influence of centralized and distributed thermal energy storage on district heating network design. Energy 202, (2020).

17. Guelpa, E. Impact of thermal masses on the peak load in district heating systems. Energy 214, (2021).

18. Luc, K. M., Li, R., Xu, L., Nielsen, T. R. \& Hensen, J. L. M. Energy flexibility potential of a small district connected to a district heating system. Energy Build. 225, (2020).

19. Turski, M. \& Sekret, R. Buildings and a district heating network as thermal energy storages in the district heating system. Energy Build. 179, 49-56 (2018).

20. Vandermeulen, A., Van Oevelen, T., van der Heijde, B. \& Helsen, L. A simulationbased evaluation of substation models for network flexibility characterisation in district heating networks. Energy 201, (2020).

21. Hammer, A., Sejkora, C. \& Kienberger, T. Increasing district heating networks efficiency by means of temperature-flexible operation. Sustain. Energy, Grids Networks 16, 393-404 (2018).

22. Chicherin, S., Junussova, L. \& Junussov, T. Minimizing the supply temperature at the district heating plant - dynamic optimization. E3S Web Conf. 118, (2019).

23. Chicherin, S., Junussova, L., Junussov, T. \& Junussov, C. Optimizing Industrial Facility's Demand for Combined Heat-and-Power (CHP). in Sustainable Development of Water and Environment (ed. Jeon, H.-Y.) 287-295 (Springer International Publishing, 2020).

24. Junussova, L., Zhuikov, A., Matiushenko, A., Chicherin, S. \& Ilicheva, A. Assessing building energy efficiency with the help of specific heat demand characteristics: boreal regions of Russia case study. E3S Web Conf. 208, (2020).

25. Leśko, M., Bujalski, W. \& Futyma, K. Operational optimization in district heating systems with the use of thermal energy storage. Energy 165, 902-915 (2018). 